\title{
Intonation in Spanish Classroom-style Didactic Speech
}

\author{
Rajiv Rao \\ University of Wisconsin-Madison, USA \\ Email: rgrao@wisc.edu
}

\begin{abstract}
Work on intonation, especially related to Spanish, has not focused extensively on second language acquisition in general. Within this context, little to no research has addressed how language instructors use rhythm and melody to facilitate the oral comprehension of language learners. This study begins to enter this space by analyzing recordings of Spanish language instructors reading passages directed at first year language students. The main results reveal that the these language instructors indeed employ intonational strategies such as pitch range expansion, early peak alignment, increased time and extent of pitch rises, less pitch reduction, and stress addition. All of these characteristics corroborate and expand upon previous literature on narrow focus and emphatic speech styles in Spanish. In this case, phonetic cues are produced to create special emphasis on words that are of particular interest to students when answering oral comprehension questions on a written exam. The concluding remarks hope to spark future perceptual studies that will help us gain a more complete picture of how didactic speech benefits learners with low levels of proficiency.
\end{abstract}

Index Terms - Spanish, intonation, didactic, stress, teacher talk, prosody

\section{INTRODUCTION}

The study of Spanish intonation has shown significant growth in the past two decades, in large part due to the Autosegmental-Metrical (AM) model (Ladd, 1996, 2008; Pierrehumbert, 1980; Pierrehumbert and Beckman, 1988). This approach has been implemented in many studies that describe the function of intonation and its phonetic and phonological properties in a wide variety of contexts in both laboratory and spontaneous speech, such as declaratives with different focus types, absolute and pronominal interrogatives, imperatives, and the chunking of discourse into phrases (Beckman et al., 2002; Face, 2000, 2001, 2002, 2003, 2006, among others; Hualde, 2002, 2003; Nibert, 2000; Prieto et al., 1995, 1996, 1998; O'Rourke, 2005, 2006; Sosa, 1999; Willis, 2003; among many others). These aforementioned studies mainly revolve around native speakers of various dialects, with studies involving the connection between second language (L2) learners and intonation being much less common. Those that do exist, such as Henrikson, Geeslin, and Willis (forthcoming), focus on production issues related to the learners themselves. Additionally, those such as Chun (2002) have discussed the theory and practice of teaching intonation in the classroom. We must also consider the role of instructors, who regularly utilize prosodic strategies to accommodate the perceptual needs of beginning level students in an L2 context. This involves a type of didactic speech style specifically geared toward teaching and pedagogical situations (Šlédrová, 2000). One of the few studies that examine instructors' use of prosody in didactic speech is Faraco et al. (2002), whose work on Italian demonstrates a connection between cues such as initial and final pauses, higher intensity, and slower tempo, and better note-taking among L2 learners. In another study on didactic speech, Gerard and Dahan (1995) find durational changes to be crucial to the identification of target words. Therefore, we see that prosodic strategies may help alleviated the cognitive demands of L2 comprehension. On a related note, Kijak (2009) points out that speech processing of the prosodic correlates of stress is much more difficult in the L2 when stress information is not as crucial to communication in the first language (L1). Overall, while such studies outline the importance of prosody in L2 situations, previous work has yet to shed much light on ways in which Spanish (or any language) language instructors use prosodic correlates such as duration, fundamental frequency (F0) movement, and intensity in pedagogically oriented didactic speech.

Tailoring speech based on other interlocutors involved in interactions is seen as crucial in sociolinguistic approaches like Speech Accommodation Theory (Giles, 1980), as well as in cases of child-directed (namely infant-directed) speech and 'teacher talk' in L2 classes. Concerning adult-to-child versus adult-to-adult speech, previous work has uncovered that adults tend to produce the following when speaking to children: exaggerated F0 movement, especially at the ends of utterances, and F0 as the most salient indicator of stress (Fernald, 1989; Fernald and Mazzie, 1991; Papoušek et al., 1991; Trainor and Desjardins, 2002; Uther et al., 2007). These tendencies appear to be more or less common, regardless of language or culture. Specifically, Uther et al. (2007) finds pitch excursions and positive affect to be significantly higher in speech to infants when compared to speech directed at second language learners of British English. In general, these phonetic cues aim to be attention-grabbing, phonologically informative, and emotionally charged (Uther et al., 2007). Furthermore, teachers' style of speech toward beginning language students helps the effectiveness of lectures as well as learner outcomes (Yanfen and Yuqin, 2010). According to Chaudron (1988), some of the main aspects of 
teacher talk deal with slower and louder speech, increased pause length, vocabulary simplification, use of fewer marked syntactic structures, and higher rates of self-repetition (see Ellis, 1994; Yanfen and Yuqin, 2010 for more recent reviews). However, Chaudron (1988) also mentions that both segmental phonology, in addition to suprasegmental issues such as stress and intonation have received little attention in the realm of teachers' speech to students (for an example, see Mannon, 1986). Due to this apparent research gap, the present study aims to outline some major melodic trends found in the production of classroom-style didactic speech by instructors of first year Spanish classes. The speech samples of three native speaker instructors come from readings of oral comprehension sections of exams. Upon comparing the intonation of didactic speech to normal read speech by the same speakers, we discover that the former variety leads to alterations in overall F0 range, F0 peak alignment, rises, and falls, as well as the presence of secondary stress in pretonic syllables.

Before discussing further specifics of the current investigation, it is necessary to summarize relevant concepts. The remainder of this paper is organized as follows: Section 2 provides a general overview of issues related to Spanish prosody, Section 3 describes the methods and materials employed in data collection and analysis, Section 4 illustrates the main F0 trends observed, and Section 5 discusses the implications of the findings and motivates future research avenues.

\section{OVERVIEW OF LITERATURE ON SPANISH PROSODY}

AM theory was created by Pierrehumbert (1980) and subsequently further explored by those such as Beckman and Pierrehumbert (1986), Gussenhoven (2004), Ladd (1996, 2008), Pierrehumbert and Beckman (1988), and Pierrehumbert and Hirschberg (1990). The model is autosegmental because tones are placed on their own phonological level or tier and are seen as units that behave independently while also maintaining association with other phonological units. The metrical label comes from the fact that tones are affiliated with metrically strong units, or stressed syllables, which are deemed stronger than unstressed syllables. Tones and syllables are placed on separate phonological tiers. These two entities are autonomous even though their tiers share association in that tones from the tone tier are linked to metrically strong stressed syllables of the syllable tier (Face, 2001).

AM theory interprets any intonation contour by utilizing two phonological tones, a high tone (H) and a low tone (L), with intervening material between tones being the result of phonetic interpolation (Hualde, 2003). Another fundamental aspect is the pitch accent, which is associated to the stressed syllable and has a single tone (H or L) or a two-tone sequence $(\mathrm{H}+\mathrm{L}$ or $\mathrm{L}+\mathrm{H})$. Pitch accents associate in different ways with the stressed syllable. For example, two pitch accents that are $\mathrm{H}+\mathrm{L}$ tonally can still be phonologically distinct; even though a whole pitch accent is affiliated with a stressed syllable, just one tone is said to be autosegmentally associated with the stressed syllable. The tone that is associated with the stressed syllable is that which establishes the alignment of the pitch accent (Pierrehumbert and Beckman, 1988). As such, alignment and association are distinguished based on the former being on the phonetic level, related to the timing of F0 and segmental events, while the latter is a more abstract idea pointing to two entities staying unified (Ladd, 1996). However, association does not allow the prediction of alignment. In AM convention, an asterisk (*) is placed next to a tone that is associated with a stressed syllable. As such, some possible pitch accents are as follows: $\mathrm{H}^{*}, \mathrm{~L}^{*}, \mathrm{H}^{*}+\mathrm{L}, \mathrm{H}+\mathrm{L}^{*}, \mathrm{~L}^{*}+\mathrm{H}$, and $\mathrm{L}+\mathrm{H}^{*}$. The tone bearing* aligns with the stressed syllable while a tone lacking * manifests itself at a phonetically determined location before or after the starred tone.

Another concept dealing with tonal association is that of phrases, which allows for the parsing of discourse into meaningful units. The phrase boundary is crucial since it represents the part of the phrase with which tones are associated. The highest level of phrasing is intonational phrasing, which is present in all languages. Another level of phrasing that is present in English, and is believed to be present in Spanish by those such as Nibert (2000), is that of the intermediate phrase. This level is below the intonational phrase because the boundary between intonational phrases is related to a stronger and clearer break in discourse than the boundary between intermediate phrases. An intonational phrase contains one or more intermediate phrases, thus the end of the final intermediate phrase in an intonational phrase is also the end of the entire intonational phrase, meaning two boundary tones will be present at this juncture. A tone (T) ( $\mathrm{H}$ or $\mathrm{L}$ ) carrying \% marks the ends of an intonational phrase, while $\mathrm{T}$ - indicates the conclusion of an intermediate phrase.

In terms of specific intonational patterns, one trend that has been found in most dialects outside of Argentina (see Toledo, 2000) is that F0 peaks in prenuclear (i.e. non-final) sentence or phrase position show displacement past the stressed syllable in broad focus, which is when one word or portion of an utterance is not emphasized more than the rest of the utterance. Words in broad focus have F0 movement that normally begins at the beginning of the stressed syllable and culminates in a post-tonic syllable. As such, these items carry an $\mathrm{L}^{*}+\mathrm{H}$ pitch accent. ${ }^{1}$ Declaratives in broad focus generally demonstrate F0 movement at or near stressed syllables, gradual peak decay (i.e. downstepping), and final lowering of F0 (Face, 2000, 2001, 2002; Hualde, 2002; Prieto et al., 1995, 1996; among others). In nuclear sentence position, F0 peaks often align with the stressed syllable due to the presence of an upcoming phrase boundary that blocks displacement. Due to this early alignment, broad focus nuclear pitch accents are often of the $\mathrm{L}+\mathrm{H}^{*}$ (followed by a boundary tone) variety.

\footnotetext{
${ }^{1}$ See Face (2010), Face and Prieto (2007), Hualde (2002), Nibert (2000), and Prieto (1998) for alternative analyses of Spanish pitch accents.
} 
Furthermore, narrow focus, which is when one word or part of an utterance is highlighted more than other items, can be signaled using syntax or prosody in Spanish (Face, 2001; Zubizarreta, 1998). It is broken down into two types, contrastive and non-contrastive. Contrastive focus is when one item is contrasted with a set of items and noncontrastive elements possess emphasis without such contrast (Face, 2001). In terms of the prosody of declaratives, previous work finds that early F0 peak alignment, increased peak height, duration, and intensity, all may play a role in conveying narrow focus (de la Mota, 1995, 1997; García Lecumberri, 1995; Face, 2000, 2001, among many others; Toledo, 1989; among others). Earlier peak alignment means that narrowly focused words often contain an $\mathrm{L}+\mathrm{H}^{*}$ pitch accent. Studies have also found that changes in pitch range occur in both pre- and post-focal peaks. In particular, postfocally, F0 is often suppressed to a flat or absent F0 contour (Face, 2001; O'Rourke, 2005; among others). Figures 1 and 2 provide schematics of broad and narrow focus excursions.

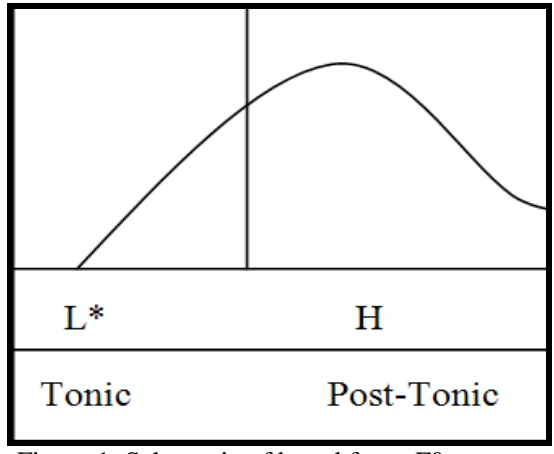

Figure 1: Schematic of broad focus F0 contour

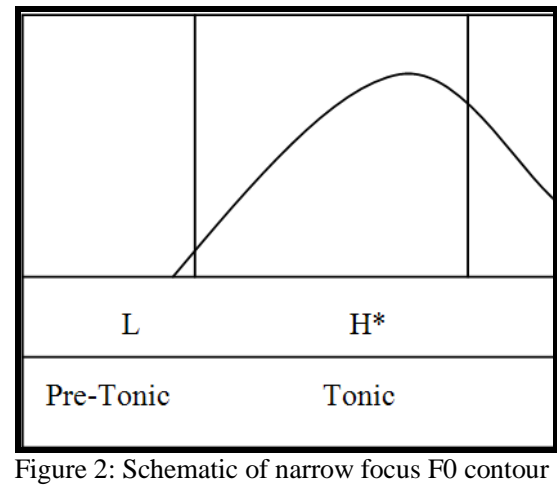

Figure 2: Schematic of narrow focus F0 contour

Another body of research is dedicated to the prosodic correlates of stress in Spanish. Stress is distinguished from accent in that the former is associated with perceived prominence of lexical items, while the latter refers specifically to F0 excursions that serve as one possible cue to said prominence (Ladd, 1996). There is a consensus among many scholars that F0 increases represent the most robust cue to stress in Spanish (Face, 2003; Garrido et al., 1993; Garrido, 1996; Quilis, 1993). These thoughts diverge from older studies that found intensity to be a strong correlate of stress (Contreras, 1964; Navarro Tomás, 1964). Fairly recent work recognizes that duration and F0 may actually both signal prosodic salience (Ortega-Llebaria, 2006). Furthermore, in cases of an absence of observable F0 movement (i.e. deaccenting), duration and intensity can both participate in cuing stress (Ortega-Llebaria et al., 2007). Previous work has also taken interest in the factors that influence deaccenting in different speech styles. For example, Face (2003) discovers this phenomenon to be more common in spontaneous speech rather than lab speech, which could be attributed to increased speech rate. Inspired by Face's (2003) study, Rao's (2009) analysis of spontaneous speech reveals that the odds of deaccenting increase in words that are shorter, commonly used in Spanish, recently repeated in discourse, categorized as verbs or adverbs, and located in non-final phase positions.

Regarding prominence, 'content' words (as opposed to 'grammatical' words such as prepositions and definite pronouns) generally permit one syllable that is lexically specified to receive stress. ${ }^{2}$ One exception to this is adverbs that end in -mente (the derivational suffix '-ly'), which are generally believed to contain 2 lexically stressed syllables (Quilis, 1993). Hualde's (2007) thorough discussion of Spanish stress states that post-lexical secondary stress is a feature present in emphatic speech styles. ${ }^{3}$ In such cases, non-lexical stress is added to syllables to the left of the lexically specified stressed slot. He divides secondary stress into two types, rhythmic and emphatic. The rhythmic type is found in a speech style deemed as 'didactic,' which, within the examples from Hualde (2007), refers to different types of broadcasts. The commonality between this context and earlier references to didactic speech is that both attempt to convey important information to an audience in an attention-capturing manner. In particular, in rhythmic secondary stress, Hualde (2007) (following Kimura, 2006) claims a H(L)H* pitch accent that accounts for the peaks on both the secondarily and lexically stressed syllables. In general, this pattern is common before syntactic boundaries, but not at the conclusion of thoughts, since the tonal sequence is often followed by an H- phrase boundary, which is indicative of the continuation of an idea. A hypothetical example of a word containing this pattern is principal ('principle') where the final syllable receives primary stress and the first syllable has secondary stress. There would be a peak on each of those syllables and possibly a valley associated with the middle syllable. On the other hand, emphatic secondary stress manifests itself in a distinct fashion. Here, an $\mathrm{H}$ tone is present on the first syllable of stressed words, followed by a drastic fall to an L- boundary tone. Such a contour is more likely to occur in turn-final position in discourse. When a word like principal undergoes an emphatic reading, the first syllable, prin, will be associated with a peak, followed by a decrease in F0 to an L- at the end of pal. Hualde (2007) believes that distinguishing between two types of secondary

\footnotetext{
${ }^{2}$ Different speech styles or communicative functions, such as highly emphatic speech, can lead to grammatical function words carrying stress (see Hualde, 2007, 2009).

${ }^{3}$ As Hualde (2007) notes, secondary stress in English is different because it is a language with unstressed vowel reduction. As such, any syllables other than the lexically stressed one that contain full vowels are seen as secondarily stressed in English. Due to lexical contrasts that can be created between the presence or absence of full vowels, secondary stress is seen as a lexical process in English.
} 
stress is important because each one serves different pragmatic functions. The rhythmic type implies that the listener should continue to stay-tuned for crucial information, while the emphatic type keys in on one specific lexical item.

Inspired by the review of previous literature, the present study aims to address the following research questions about Spanish intonation: i. What are the main F0 features involved in classroom-style didactic speech?; ii. How does this speech style distinguish itself from normal read speech (to a fellow native Spanish speaker)?

\section{METHODOLOGY}

The didactic speech data set comes from three early 30s male speakers of similar dialects of Peninsular Spanish, all of whom have taught elementary and intermediate levels of Spanish language classes in the United States for at least five years. ${ }^{4}$ Therefore, they are well versed in tactics that may help students key in on words that are crucial to the understanding of oral language. These three particular speakers also have comparable voice quality, meaning their average F0 lies within a similar range. In order to elicit a didactic speech style, the subjects were instructed to read a series of five passages as if they were reading them to their first year language students. The passages, each containing approximately 100-150 words, were all extracted directly from oral comprehension sections of exams previously administered in first year Spanish language classes at a university in the United States. Each one dealt with vocabulary and main themes of textbook chapters, which led to productions on topics ranging from the role of the mother in Latin America, to a description of a narrator's disastrous day. The instructors had an idea of which pieces of information were most central to the students' understanding of each passage. Although the subjects were not in the natural context of the classroom, this type of data collection methodology, in which non-naïve speakers produce speech that they envision as appropriate for certain situations, has been employed by at least Hualde (2002), Rao (2006), and Rao (2010). Therefore, even though the subjects were in a controlled environment (in a quiet room, wearing a head-mounted microphone connected to a laptop computer), these speech samples can be seen as representative of the didactic speech they would use with students. Furthermore, in order to have an object of comparison, the speakers also read all passages at a 'normal' speech rate, or the manner in which they would read to a native-speaker friend. Here, 'normal' is defined as approximately 5-7 syllables per second, following Marín-Gálvez (1994). It is important to mention that from here on out, our discussion of the labels 'didactic' and 'normal' speech styles implicitly carry the notion of 'read' as well.

Following data collection procedures, the F0 excursions in or around the stressed syllables of 2,445 stressed words were analyzed using the Praat software package (Boersma and Weenink, 2009). ${ }^{5}$ Such excursions are crucial to stressed words in Spanish because they are arguably the strongest phonetic signal of prominence (Face, 2003; Hualde, 2002; Navarro Tomás, 1944; Quilis, 1993; among others). Identifying categories of stressed items in Spanish was done by referring to the lists provided in Quilis (1993). Before the detailed look at F0, all words were coded for speech style and speaker. All unstressed items, such as prepositions, definite articles, and conjunctions were excluded from the group of analyzed tokens. ${ }^{6}$ A small group of stressed tokens also had to be discarded due to recording issues. Regarding F0 movement, each stressed word in both didactic and normal speech was measured for rise and fall time in milliseconds (ms), peak height, alignment with or displacement from the stressed syllable, and secondary stress. An F0 excursion had to measure at least 7 hertz (Hz) in order to be considered a peak (based on O'Rourke, 2006; Rao, 2009; Willis, 2003). Once all measurements were taken, a series of paired t-tests statistically evaluated the differences between didactic and normal speech styles with regard to the phonetic variables in question. Based on relevant trends cited in earlier work, one could anticipate any of the following in didactic speech, when compared to normal speech: faster rises leading to earlier peak alignment, higher peaks, few to no cases of deaccenting, and the presence of secondary stress in words of at least three syllables. Based on this phonetic evidence, phonological pitch accents were then assigned to words.

\section{RESULTS}

This section presents a series of F0 contours illustrating the main trends discovered in both didactic and normal speech. The visual representations of differences between speech styles inform us of phonetic strategies that Spanish language instructors implement when communicating important information to their students. The main objective of this section is to introduce some phonetic and phonological tendencies observed in didactic speech, rather than provide an extremely rigorous statistical analysis of the data. Unless noted, the figures provided occur regularly in the data from all speakers.

An example of a word illustrating narrow focus tendencies in didactic speech is provided in Figure 3 . In this case, the word problemas ('problems') seems to be emphasized in the phrase cuando hay problemas ('when there are problems'). This word is important to the passage because students needed to ascertain the roles of the mother in the household

\footnotetext{
${ }^{4}$ Due to technical difficulties, we will not consider the normal read speech of one speaker in this study. The main differences cited will rely on the two speakers that successfully produced both normal and didactic samples.

${ }^{5}$ Intensity, which is another potential correlate of stress and/or narrow focus in Spanish, was also measured in the data set. Overall, didactic speech yields significantly higher intensity $(\mathrm{p}<.0001)$. However, since the present paper focuses on F0, a detailed analysis of intensity, as well as duration, is set aside for future research.

${ }^{6}$ A preliminary glance at function words such as por ('by') and $e l$ ('the,' masculine) shows that such words do possess F0 rises through stressed syllables in several tokens of didactic speech even though they are not lexically specified as being stressed. The prosody of such words surely merits future investigation, as Hualde (2009) also encourages.
} 
during positive and negative times. As such, the instructor uses phonetic strategies to communicate, "this word and the upcoming information is of interest." The initial valley, at $148.2 \mathrm{~Hz}$, is associated with an L tone, while the peak, which occurs $65.5 \mathrm{~ms}$ prior to the syllable boundary of ble, at $250.2 \mathrm{~Hz}$, after a drastic $102 \mathrm{~Hz}$ rise lasting $233 \mathrm{~ms}$, is associated and aligned with this stressed syllable, and is thus labeled with an $\mathrm{H}^{*}$ tone. Therefore, we conclude that the pitch accent of this lexical item is $\mathrm{L}+\mathrm{H}^{*}$. Another relevant characteristic of this contour is a final fall of $112.6 \mathrm{~ms}$ from the $\mathrm{H}^{*}$ tone to an L- intermediate boundary tone, manifested around $165.4 \mathrm{~Hz}$. Interestingly, this phrase boundary is present even though the sentence being read does not call for a pause through some sort of punctuation. Finally, we note that a contour similar to this one is observed for the other speakers analyzed. In general, this pattern of early alignment is pervasive throughout the data, though a following boundary may or may not always be present. More examples are given in (1), all of which are words that are crucial to students correctly comprehending the passage and answering questions about what they hear. The stressed syllable evidencing narrow focus through peak alignment is underlined.

(1) Lexical items displaying the $\mathrm{L}+\mathrm{H}^{*}$ pitch accent

a. Aquí les comento el pronóstico de tiempo ('Here I provide you with the weather forecast')

b. Deben estar atentos ('You all should be alert')

c. ...no tenía plumas ('it (the bird) didn't have feathers')

d. ...mil novecientos setenta y cinco ('1975')

e. Obviamente el padre respeta esta posición ('Obviously the father respects this position')

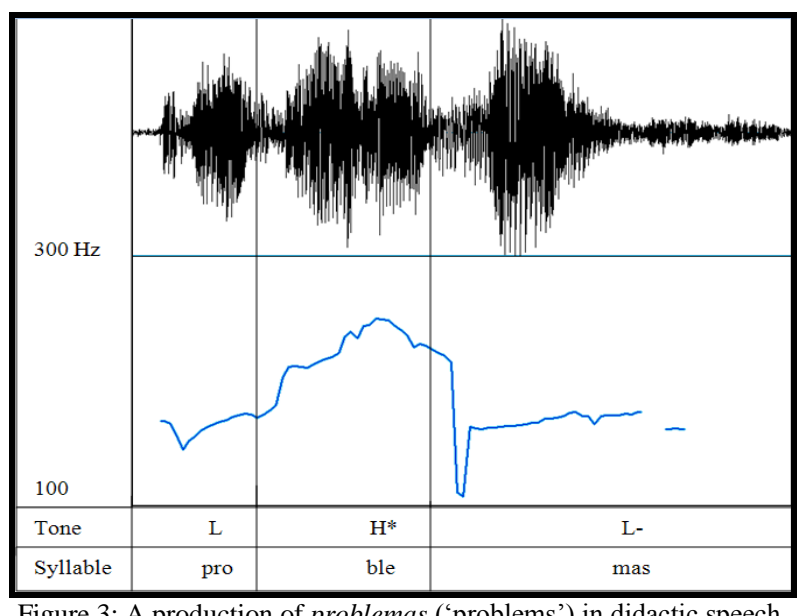

Another way of highlighting an element in discourse, which is distinct from the method in Figure 3 , is via the addition of post-lexical secondary stress. Figure 4 provides an example of an F0 contour showing emphatic secondary stress, in which the first syllable of problemas possesses an $\mathrm{H}$ tone at $181.9 \mathrm{~Hz}$, from which a steep fall of $328 \mathrm{~ms}$ occurs, ending in an L- boundary tone at $129.8 \mathrm{~Hz}$. The interesting part of this trend is that the stressed syllable ble is not associated with an F0 peak, but rather a decline. This is a rare circumstance for stressed content words in Spanish. Here, the early $\mathrm{H}$ tone, a sudden F0 decrease, and the presence of an upcoming boundary combine to highlight this communicatively important item. One key difference between emphatic secondary stress and the early alignment in Figure 3 is that the rise to a peak in the latter case is realized in a much higher pitch range than is the movement in the former. The word with early alignment is also longer in duration. Further examples of emphatic secondary stress with this same pitch accent pattern are listed in (2). The syllable with a peak is underlined, while the lexically stressed syllable is bolded.

(2) Other words produced with emphatic secondary stress

a. ...por algún ladrón ('by some burgler').

b. Era exactamente como conocemos hoy ('It was exactly as we know it today')

c. ... sus estudios de abogacía ('her studies in law')

d. ...la institución ('the institution')

e. ...la computadora que compré el mes pasado ('the computer I bought last month') 


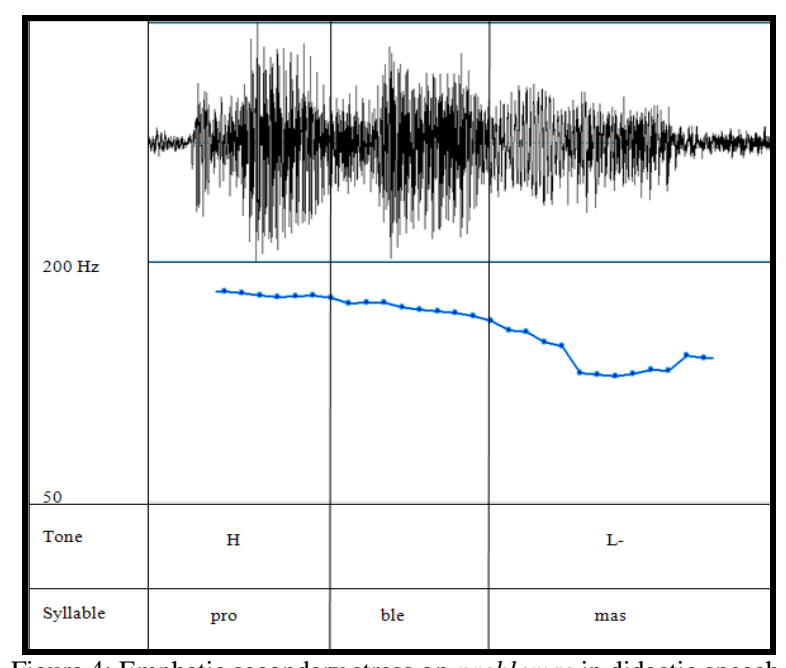

On the other hand, a faster rate of speech leads to a much different F0 contour of problemas. Figure 5, showing problemas produced in the exact same context, displays an extremely flat F0 trace, which is indicative of deaccenting. The F0 range here is much reduced, occurring around $146.5 \mathrm{~Hz}$, with no movement of over $7 \mathrm{~Hz}$, which points to the lack of any peak, or $\mathrm{H}$ tone. In fact, across the data for both speakers that produced both speech styles, pitch range is increased in didactic speech at a significant level $(\mathrm{p}<.0001)$. When comparing Figure 5 to the previous two, we note an exaggerated difference in F0 rises and falls. However, these two variables are statistically significant in different ways across the data. F0 rises and their duration of rise are increased in didactic speech $(\mathrm{p}<.0001)$ while F0 falls and fall times are increased in normal speech $(\mathrm{p}<.0001)$. These results appropriately fit in with the significant findings for pitch range. Furthermore, while extreme pitch reduction is found in both speech styles, Table 1 demonstrates that the normal style is conducive to higher levels of this phenomenon. Additionally, this word in Figure 5 does not demonstrate strong evidence of a following phrase boundary tone. It is worth noting that the other speaker did produce a pitch accent on this word at the normal speech rate, but with a limited pitch excursion (27.5 Hz rise over $184.4 \mathrm{~ms}$ ) and displacement of the peak to the following syllable $(76 \mathrm{~ms})$, both of which correlate more with broad focus rather than prominence. Finally, regardless of emphatic strategy, the word duration is longer in such cases when compared with instances such as that of Figure 5. In fact, across the entire data set, didactic speech is significantly longer, with more pauses, than normal speech.

TABLE 1:

DEACCENTING RATES IN EACH SPEECH STYLE

\begin{tabular}{|c|c|c|}
\hline Speaker & Didactic Speech Deaccenting & Normal Speech Deaccenting \\
\hline 1 & $21 \%(100 / 469)$ & $35 \%(172 / 494)$ \\
\hline 2 & $29 \%(146 / 493)$ & $37 \%(185 / 494)$ \\
\hline 3 & $19 \%(95 / 493)$ & N/A \\
\hline
\end{tabular}

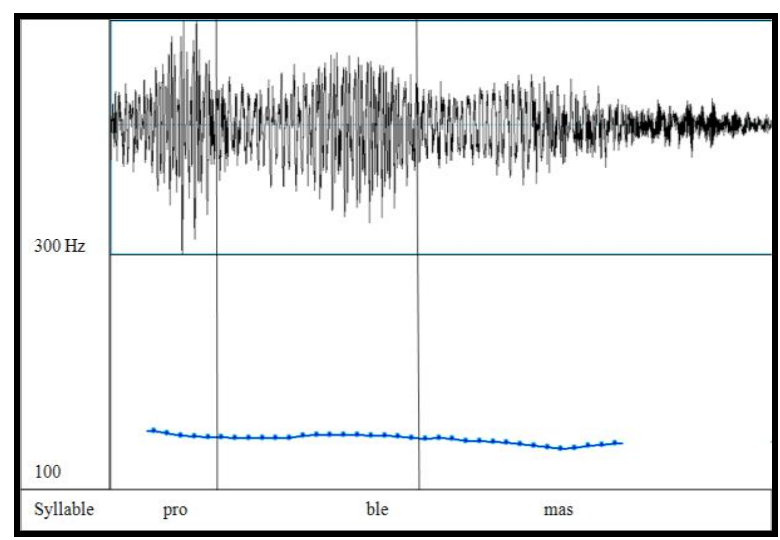

Figure 5: A production of problemas ('problems') in normal speech.

Some additional examples of deaccented words from both speech styles are displayed in (3) and (4). The words in (3) are actually commonly deaccented in both speech styles, while those in (4) do not deaccent in didactic speech.

(3) Deaccented words in didactic speech

a. es ('it is')

b. fue ('it was') 


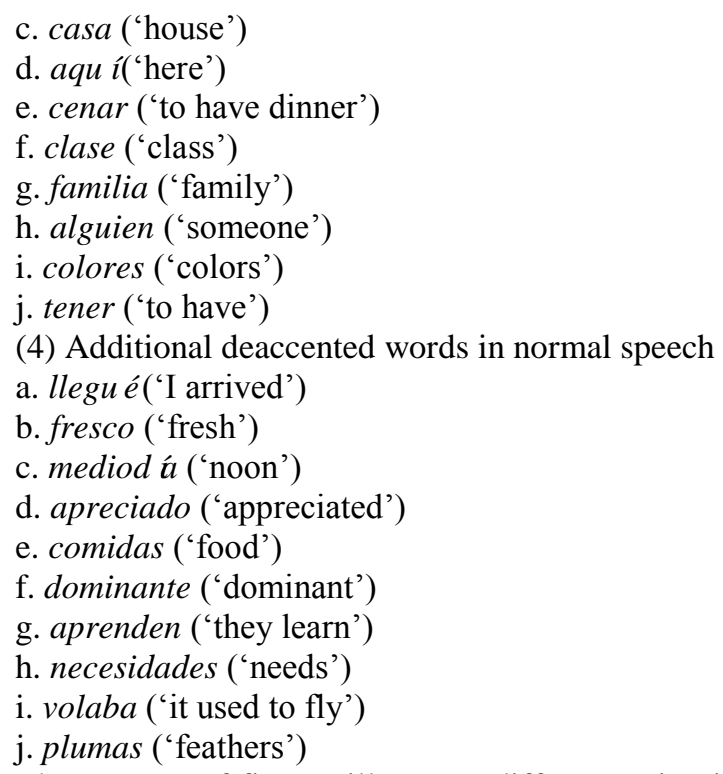

The next set of figures illustrates differences in pitch scaling between the two speech styles. In Figure 6, the phrase tiene una gran autoridad ('she has great authority') is describing the role of the mother, but without indicating that the information is particularly noteworthy to students taking the exam. As such, we observe downstepping, or gradual F0 decay as F0 progresses through the phrase. The initial valley, at $154.2 \mathrm{~Hz}$, is associated and aligned with the stressed syllable tie, followed by a rise to the $\mathrm{H}$ tone at $178.1 \mathrm{~Hz}$, which is aligned with the post-tonic syllable (which resyllabifies with the $u$ from una to produce a falling diphthong). Next, there is a drop from the first peak to the second $\mathrm{L}^{*}$ tone, which is manifested at $127.4 \mathrm{~Hz}$ and is associated with the stressed syllable gra. The second post-tonic peak, on the syllable nau (which has also undergone resyllabification) occurs at $145.1 \mathrm{~Hz}$ and is followed by the last drop to $118.1 \mathrm{~Hz}$, or the valley aligned with ri. The final peak of the phrase, which aligns with the final (and stressed) syllable of autoridad (in which the final consonant has been deleted) at $135.1 \mathrm{~Hz}$, is followed by an $\mathrm{H}$ - boundary tone indicating that the idea is going to continue. Based on previous literature, as well as the information central to the passage from which the phrase is extracted, we can assume that this downstepping is indicative of a broad focus reading. The speech of all speakers yielded a similar downtrend in this context as well as in many contexts that are not of the utmost importance for students.

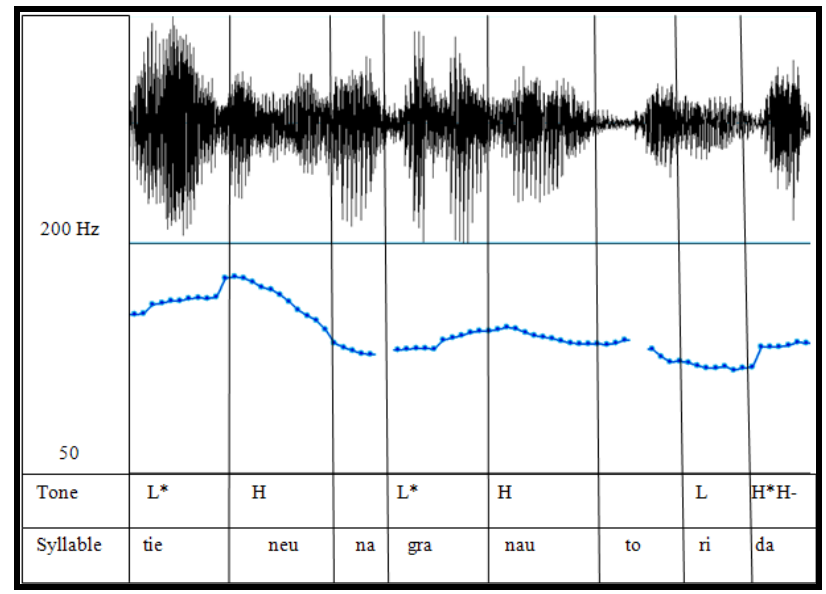

Figure 6: The phrase tiene una gran autoridad ('she has great authority') in didactic speech.

When comparing Figures 6 and 7, we note that overall F0 decay is common on both speech styles, but with differing reduction tendencies. Rather than downstep, Figure 7 shows one high peak associated and aligned with the stressed syllable tie, at $144.1 \mathrm{~Hz}$, at the beginning of the phrase, and a subsequent downslope all the way to the L tone at 111.5 $\mathrm{Hz}$, aligned with the pre-tonic syllable of autoridad. The F0 movement through gran is not large enough to generate a pitch accent. The rise to the final peak on the stressed $\mathrm{dad}$ and intermediate boundary at $135.1 \mathrm{~Hz}$ also signal that the idea has not yet reached its concluding point, which is a strategy employed in Figure 6 as well. ${ }^{7}$ Interestingly, the pitch range in which the contours in Figures 6 and 7 take place is very similar. The main difference is that the downtrend in Figure 6 exhibits more overall peaks and valleys, thus producing a more gradual downward movement when compared

\footnotetext{
${ }^{7}$ Oxytones represent exceptions to broad focus pitch accent tendencies because they generally display early alignment of peaks. Therefore, at times, it is difficult to distinguish between broad and narrow focus pitch accents in words with this stress pattern (see Hualde, 2002).
} 
to the drastic fall in Figure 7. Therefore, information that is less crucial to the passages shows both similarities and differences.

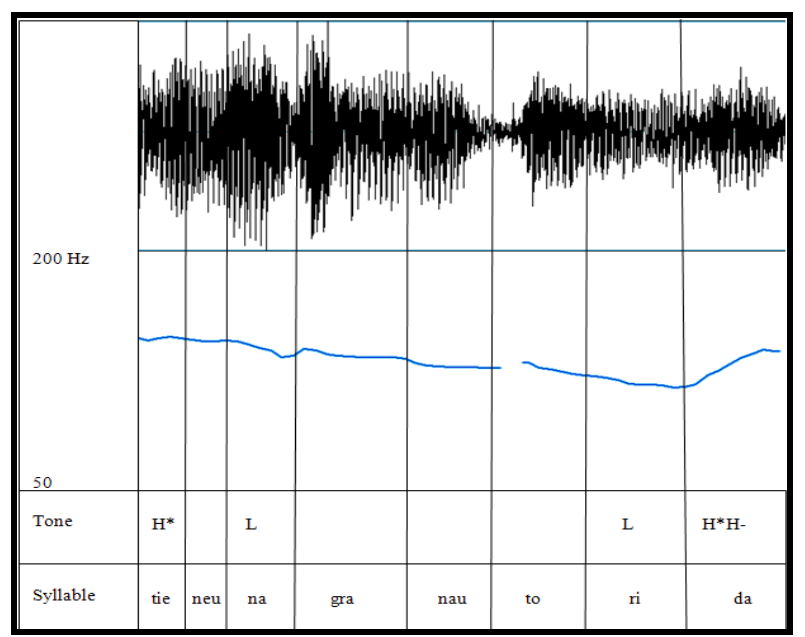

Figure 7: The phrase tiene una gran autoridad in normal speech.

Perhaps the most interesting revelation for didactic speech is the presence of both rhythmic and emphatic secondary stress. While this additional post-lexical stress only occurs in about $6 \%$ of all words that are $3+$ syllables in length, it is apparent that all such items are crucial to the students' ability to comprehend portions of the passage that will allow them to successfully answer related questions. An extreme example of rhythmic secondary stress is depicted in the F0 contour of Figure 8. This complex contour actually resembles patterns one might observe over an entire phrase, since we observe three peaks and two valleys within this one lexical item. Students taking this exam need to know how the mother handles conflicts between fathers and children. Therefore, instructors make this lexical item prominent within the phrase hace de intermediaria ('she plays (the role of) intermediary'). In terms of specific F0 movements, the H tone at $164.1 \mathrm{~Hz}$ aligned with in falls to an L valley at $139.4 \mathrm{~Hz}$. What is curious about this movement is that it all takes place within one lengthened syllable, as if the valley is a type of boundary tone within a word. The subsequent rise to the $\mathrm{H}$ tone that aligns with ter reaches $185.5 \mathrm{~Hz}$ before dropping to $140.3 \mathrm{~Hz}$ in the $\mathrm{L}$ in $m e$. The final rise to the $\mathrm{H}^{*}$ at 157.9 Hz, aligned with the lexically stressed dia, leads to a boundary tone plateau at $152 \mathrm{~Hz}$. The H- tone implies that more useful information is on its way. The main feature from this contour is that the first two peaks, both of which are aligned with syllables that are not lexically stressed, are higher than the lexically stressed peak. Also, we see evidence of the HLH* tonal sequence described by Hualde (2007) and Kimura (2006), plus the insertion of an additional pitch accent in the syllable that is furthest to the left.

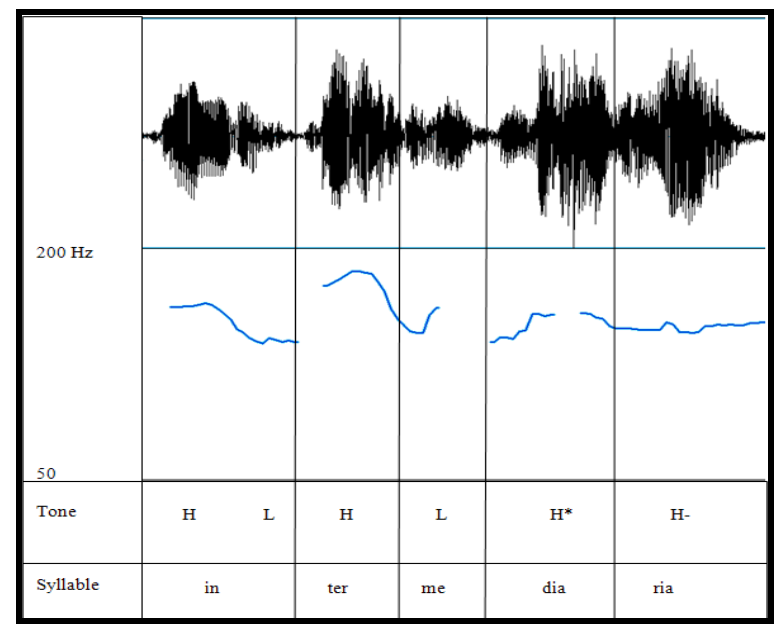

Figure 8: Rhythmic secondary stress in intermediaria ('intermediary') in didactic speech.

When comparing the F0 trace of intermediaria in Figures 8 and 9, there is a noticeable difference between speech styles. In Figure 9, the expected broad focus pitch accent, $\mathrm{L}^{*}+\mathrm{H}$ appears, with the $\mathrm{L}$ tone, associated and aligned with dia, at about $95 \mathrm{~Hz}$, and the post-tonic $\mathrm{H}$ tone manifesting itself at $110 \mathrm{~Hz}$. This rise may help cue lexical stress. The lack of a following boundary tone indicates that this word appears in phrase medial position. Furthermore, the relatively flat F0 preceding the tonic and post-tonic syllables clearly shows the absence of any other secondary accents. The final rise is almost the same as the one in Figure 8, but the overall pitch range in which the word is articulated is substantially 
lower than the didactic speech production. Therefore, we can conclude that the main points of distinction between the last two figures are the overall F0 range, as well as the presence/absence of rhythmic secondary stress.

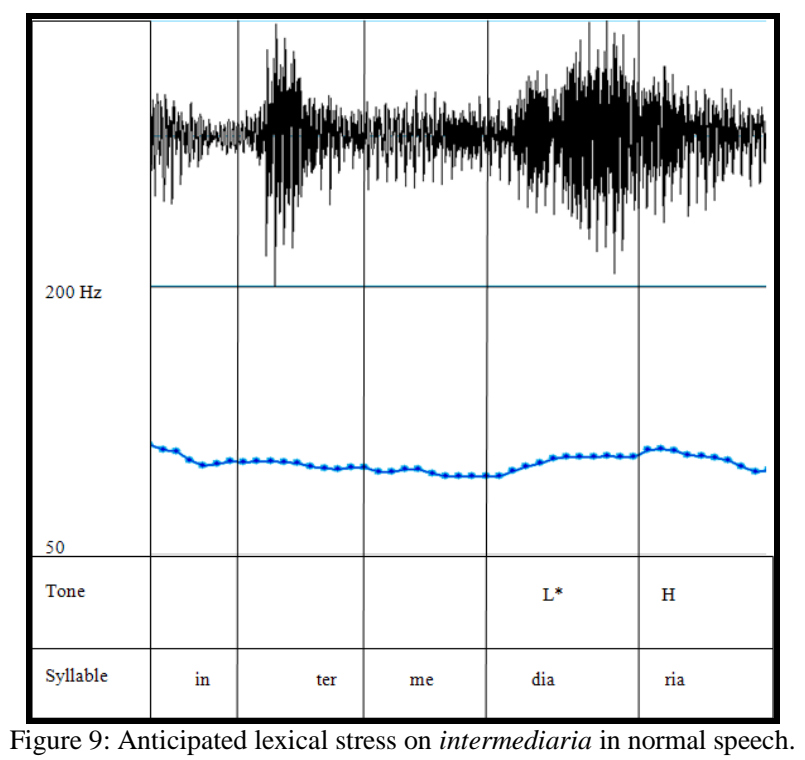

Figures 10 and 11 compare pitch accent and stress patterns in a word with four syllables rather than five. Examining Figures 8 and 10, both of which contain words that instructors hope to highlight for students, demonstrates that it is not possible for words with fewer than five syllables to contain the additional secondary stress peak found in intermediaria. In Figure 10, we once again have evidence of an HLH* contour, except in this case the L- intermediate boundary cues a slight pause in this stream of read text. The first $\mathrm{H}$ tone on in reaches its peak at $185.2 \mathrm{~Hz}$. F0 then drops to $169.1 \mathrm{~Hz}$ in the second syllable and rises to an $\mathrm{H}^{*}$ associated and aligned with the stressed $t u$ at $192.8 \mathrm{~Hz}$. This highest peak then causes pitch reduction to $155.3 \mathrm{~Hz}$, which is where the intermediate boundary appears. Other than the number of syllables and boundary tones, the main distinguishing feature between rhythmic secondary stress on intermediaria and inquietudes is the phonetic difference between peak heights. In the former example, the excursion signaling secondary stress is higher than that of the lexically specified syllable, while the latter case shows the opposite pattern. However, a couple of clear tendencies are the production of these words in similar pitch ranges, and the avoidance of secondary stress on the syllable immediately to the left of the lexical stress. Adjacent stress, which creates a clashing situation, is generally less than optimal in Spanish (Hualde 2007).

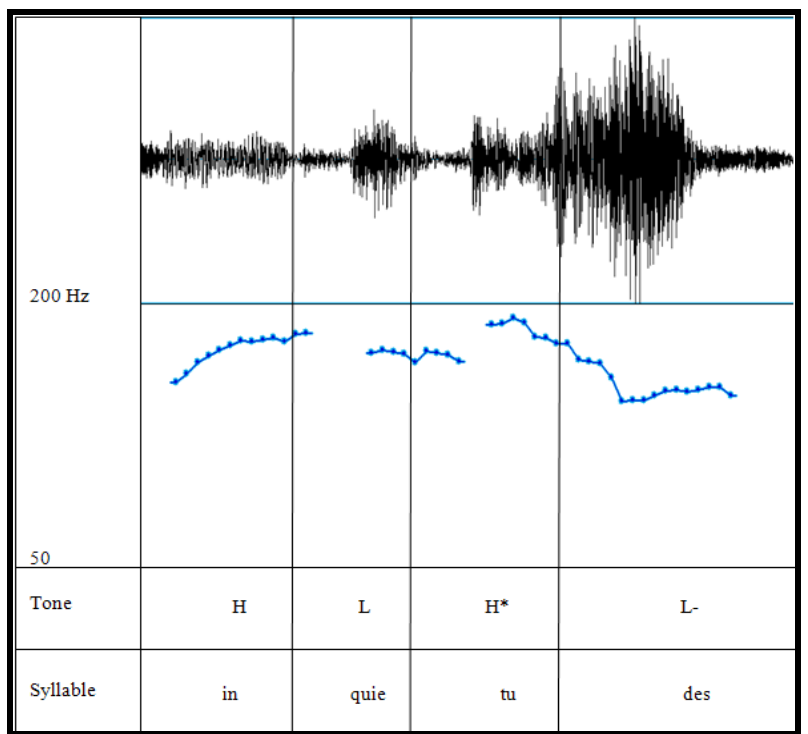

Figure 10: Rhythmic secondary stress on inquietudes ('worry') in didactic speech

More examples of words in which we find rhythmic secondary stress are given in (5). Through this list, it becomes increasingly apparent that this type of emphasis is only added to content words with a minimum of three syllables. The lexically stressed syllables are underlined and bolded and the secondarily stressed syllables are only underlined.

(5) More words with rhythmic secondary stress

a. verdadero ('truly') 
b. acompañada ('accompanied by')

c. familiar ('familiar')

d. disciplinarles ('to discipline them')

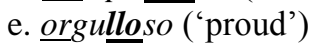

f. importaban ('important (to them)')

g. diputâda ('member of parliament')

h. Venezuela ('Venezuela')

i. tradicional ('traditional')

j. desempeñó ('(she) fulfilled')

The F0 movement in Figure 11 does not convey secondary stress, but it does evidence emphasis on the word inquietudes through peak association and alignment with the stressed syllable, followed by an intermediate boundary tone. The initial F0 traces, in the neighborhood of $108 \mathrm{~Hz}$, increase to $150.8 \mathrm{~Hz}$ when peaking in the stressed syllable. After this apex, there is suppression to $122.7 \mathrm{~Hz}$, or the location of the L boundary tone. The pitch range is significantly lower than the range of the didactic sample from Figure 10. However, the contour here is produced in a higher range than the one from Figure 9, which suggests that emphasis in normal read speech is realized in a higher pitch range than broad focus. $^{8}$ Along the same lines, a boundary tone immediately after a word may cue narrow focus, as found by Face (2001, 2002).

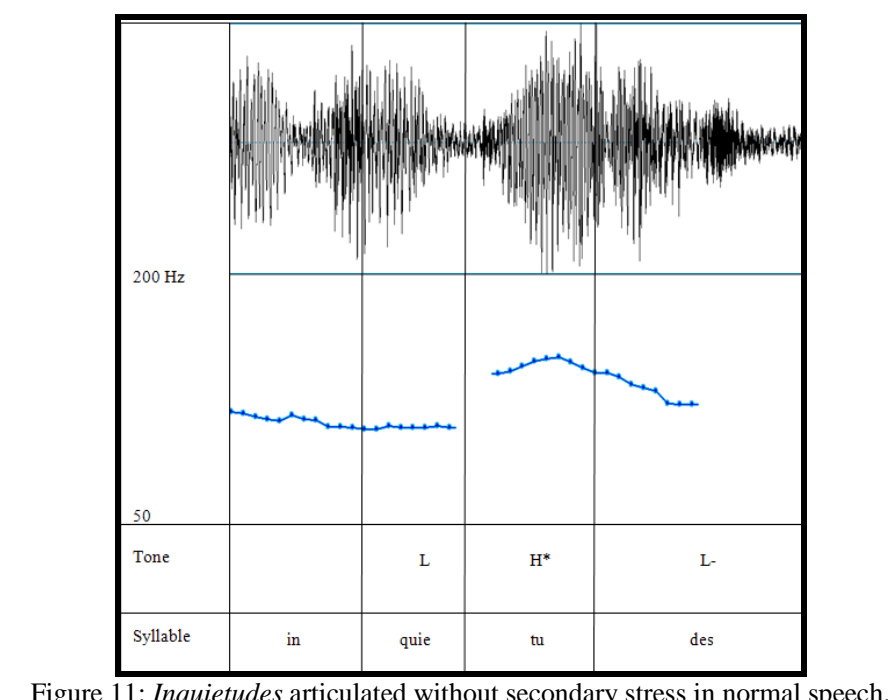

Figure 11: Inquietudes articulated without secondary stress in normal speech.

\section{DiSCUSSION AND CONCLUSIONS}

The results from the previous section reveal a number of F0 trends that play a role in signaling emphasis in didactic speech that are either reduced or absent from normal read speech. The main features observed in didactic speech are: increased overall pitch range, early alignment and following boundary tones associated with communicatively important items, less deaccenting, clear and gradual downstepping of less important phrases, and the presence of both emphatic and rhythmic secondary stress. The data from instructors of Spanish in this study appear to indicate that the aforementioned pitch alterations are made in order to aid students' listening comprehension of information that is particularly relevant to passages on exams.

The main F0 correlates of didactic versus normal speech correspond with previous literature on narrow versus broad focus, respectively. The increase in pitch range in constituents (words, phrases, utterances) conveying narrow focus has been noted for Spanish, particularly by Face (2000, 2001, 2002, among others) for Peninsular Spanish and O'Rourke $(2005,2006)$ in situations of language contact between Spanish and Quechua in Peru. In the didactic speech of the current sample, each one of the passages, which comprise entire paragraphs, is manifested in a higher pitch range when compared to productions of normal speech. Therefore, in addition to the slower speech and increased number of pauses noted by previous studies on the phonetics of teacher talk, we see that one function of increasing the range of F0 in native speaker speech is to facilitate the comprehension abilities of L2 learners. This higher range may demonstrate drastic F0 increases on words that are particularly crucial to student responses to questions, which is apparent through the significance of F0 rise and rise time in didactic speech. Parallel findings have also been discovered in previous work on narrow focus (de la Mota, 1995; Face, 2001). However, Face's (2010) recent work discussing more perceptual studies argues that peak height increases may not be enough to cue narrow focus. On the other hand, F0 falls and time of falls are longer in normal speech in the current study. Therefore, the results suggest that rises are more important to

\footnotetext{
${ }^{8}$ This is only suggestive because it is possible that duration and/or intensity may be influenced by a narrow focus production.
} 
emphasis or communicative salience, which are key methods of addressing L2 students, while more extensive falls are associated with faster, native-to-native speech that does not require a tone that draws particular attention to speech. The importance of rises is confirmed by studies dating all the way back to Navarro Tomas (1944). Therefore, we conclude that longer and larger rising pitch excursions are another method that instructors utilize in didactic speech.

As previously pointed out, severe rises and falls are also characteristic of infant-directed speech. As such, we can draw a connection between first year language students and infants, both of whom are in the fledgling state of the acquisition of a language. The L2 students listening to the passages used here are linguistically 'infants' when it comes to Spanish. Therefore, it makes sense that instructors feel the need to produce cues similar to those in infant-directed speech. However, the fact that L2 learners normally have a solid linguistic foundation in their first language may allow them to more easily recognize certain prosodic trends, which would not necessitate as much exaggeration. For example, the overall F0 movement found in earlier research (rises and falls) on infant-directed speech may attract more attention than just the significant upward excursion revealed here for L2 student-directed speech. Based on these preliminary insights, comparative studies of didactic speech along the lines of Uther et al. (2007) are definitely needed.

Coupling the results for F0 rise with the common trend of early alignment permits us to further the discussion of F0 in didactic speech. Previous work has found that early alignment is not conducive to larger increases in F0 scaling because this leftward movement of peaks decreases the time available for F0 to climb (for example, Face, 2001). However, in didactic speech, early alignment also occurs with significantly longer and larger pitch excursions. Since the F0 rise is generally anchored to the beginning of the stressed syllable, the overall duration of the stressed syllable must be increasing if a peak is realized as an $\mathrm{H}^{*}$ tone because otherwise there would not be enough time available for F0 to increase and still be manifested within the stressed syllable. As such, we can begin a discussion of overall duration differences even though this was not a specific variable measured in this study. Though duration, as previously mentioned, is an important correlate of both stress and narrow focus, this suggestion merits future research in didactic speech.

Furthermore, concerning pitch scaling, in the reading task directed toward L2 learners, the instructors used here produce gradual downstepping across phrases, with visible F0 peaks. Conversely, a steeper drop without peaks is more common for the normal speech style. Based on these trends, the fact that F0 peaks are present in general in speech directed to L2 learners is important. While such peak decay has previously been associated with broad focus (Prieto et al., 1995, 1996), the results here indicate that it definitely reflects slower speech, that is overall more animated and engaging, even when the items tied to downstep are not the most communicatively heavy. That is, it could be the case that downstep and related peak displacement are a manner of keeping the audience involved and attentive by facilitating comprehension, but at the same time distinguishing less important information from more important information, the latter of which is cued through increases in F0 and earlier peaks. When speech does not need to be as catchy as teacher talk, it presents more severe drops in F0 without as many peaks.

The current data displays cases of deaccenting in both speech styles. However, upon comparing examples such as those in (3) and (4), it becomes clear that the types of lexical items that are subject to such pitch reduction are different in each speech style. The deaccented words in didactic speech (see (3)) are all either short in length, common across the Spanish language, previously repeated in the passage, or some combination of these factors. Such words are seen as semantically light and thus articulated with less F0 movement by instructors. This explanation fits into the scheme of Rao (2009), who finds all three of the reasons given here to be relevant to deaccenting in spontaneous speech. ${ }^{9}$ The deaccented items in normal speech are on average longer than those in didactic speech and less common across Spanish, but they do represent information that is either repeated or obvious based on the passage at hand. Therefore, examining didactic speech, faster read speech, and the spontaneous speech from Rao (2009), leads to the emergence of a type of continuum of permissible words to deaccent based on speech style that may be based on hearer involved. In more animated read speech directed at L2 learners, shorter, common, or given words are subject to deaccenting, while faster read speech addressing native speakers allows for pitch reduction of longer words, provided that they are repeated. In spontaneous interviews, Rao (2009) finds all of these to be common, along with phrase position and grammatical category. We do find that the slower rate of didactic speech results in phrases with fewer stress words (on average 1-2 per phrase) than phrases in normal speech (3-4 words per phrase). However, further details connecting phrasing and didactic speech remain for further exploration.

Finally, F0 contours representing both emphatic and rhythmic secondary stress confirm the thoughts of Hualde (2007) and Kimura (2006) for other types of didactic speech. Here, we expand on those studies by showing that the $\mathrm{H}(\mathrm{L}) \mathrm{H}^{*}$ tonal sequence conveying rhythmic secondary stress does indeed manifest itself in classroom style didactic speech. Furthermore, as suggested by both Hualde and Kimura, rhythmic secondary stress tends to occur in the middle of a sentence, or a non-terminal break. Even when there is a following boundary tone, the subsequent pause is very short. However, in cases of emphatic secondary stress, there is always a boundary tone followed by a slightly longer pause. This makes sense, given that boundaries appearing directly after lexical items are one strategy of implying emphasis, according to Face (2002). The fact that these examples of post-lexical secondary stress are present in didactic speech and absent from normal speech indicates that stress addition is a possible way to grasp the attention of those speakers

\footnotetext{
${ }^{9}$ Rao (2009) defines a 'common' word in Spanish as one that receives at least 2,000 hits in the $20^{\text {th }}$ century in the Corpus del español (Davies 2002).
} 
with lower levels of linguistic competence and thus help them tune into lexical items that are paramount to their understanding of a passage. Whether or not this type of added emphasis is more effective than strategies such as early alignment and increased F0 scaling is an idea that has rarely been addressed in previous work and that deserves a future look.

Moreover, with respect to F0 peaks in words with secondary stress, there does not seem to be a clear trend of one peak being higher than the other, though the peak with secondary stress generally appears two syllables to the left of primary stress, as predicted by Hualde (2007). Examples of both main and secondarily stressed peaks being larger are found in the present data. Perhaps it is the case that peaks helping signal secondary stress somehow increase salience of a lexical item. The possible effects and interpretations created by such peak height alterations also represent an intriguing object of future research.

One last note to be discussed is only revealed in one word in the data, intermediaria. In this case, while all speakers produce secondary stress in didactic speech, only one creates extreme lengthening of the first syllable, in. This durational increase leads to an $\mathrm{H}$ and $\mathrm{L}$ tone being manifested within the same syllable, which is a rare occurrence. The F0 drop reflects a word with an L- intermediate phrase boundary, though in this case it appears as if there is a boundary within a lexical item. This situation has rarely been attested for other speech styles in Spanish, and also figures to be problematic for the AM model, which does not account for any sort of word-internal boundaries. This idea may or may not be important. However, there seems to be some relevance because this drop to a 'pseudo-boundary tone' could be the factor that allows for an $\mathrm{H}$ tone on the first syllable of this word. A word of five syllables, such as intermediaria, apparently also can manifest more than two H tones, as we observe in the present data. This means that another HL can be added to the left of the tonal sequence proposed by Hualde (2007) and Kimura (2006), which raises the question as to how many of these additional high-low fluctuations can be added to a word. Is it possible that cases of rhythmic secondary stress permit an HL on all syllables that stand to the left of the stressed one (given that they are all at least one unstressed syllable away from the stressed one)? A future look at longer words with secondary stress will help us answer this question.

The discussion to this point sheds light on how Spanish instructors incorporate different types of rhythm and melody into their speech in order to assist students in oral comprehension. The results corroborate and build upon older related studies. However, all the results are production based. In order to gain a clearer sense of how students benefit from these supposed melodic correlates of emphasis, future studies should focus on the perception of classroom style didactic speech (or any other speech style) by students. To this point, in general, studies on the production of Spanish intonation far outnumber those focused on perception. Until scholars delve into perception in more detail, we will have a somewhat unclear picture of the effects or benefits that listeners receive from cues that seem to create emphasis on specific constituents that, for example, help them answer questions on an oral comprehension exam. This study hopes to be a building block, or initial step toward a more complete picture of how prosody contributes to oral comprehension in the classroom.

Lastly, the limitations of this study must be set forth, as they will hopefully inspire future methodological innovation. This data set comes from a small number of male speakers from one region of Spain. Future studies should aim to cover a larger range of speakers, perhaps from different geographic regions, as well as different age groups and genders. Based on previous work on dialectology, one would expect different realizations of didactic speech based on any (or multiple) of these factors (see Lipski, 1994; Sosa, 1999). Also, other prosodic variables, such as intensity and duration, which have been found to play a role in the prosodic manifestation of narrow focus, should be investigated with respect to didactic speech. It may be the case that one or both of these measures show even more effects than F0. They may even combine with F0 to create increased perceptual salience. We should also attempt to collect data from instructors addressing their students in real-time in speech that is not only of the read variety. While this is methodologically challenging, it would generate the most 'natural' data and allow for a more broad commentary on classroom-style didactic speech. Comparing in-class data to this study would potentially illuminate the effect of the physical presence of the L2 students.

Overall, this study is one phase of what will hopefully turn out to be a series of studies on didactic speech, or teacher talk, conducted by the field at large. The current findings contribute to our knowledge of Spanish intonation in a unique speech style, while also motivating and encouraging the pursuit of further work in this area. Ultimately, the goal is for future production and perception studies to gain momentum in the field of Spanish phonetics and phonology, as well as second language acquisition.

\section{APPENDIX}

This paragraph is an example of one of the texts read by the language instructors in this study.

En el mundo hispano la institución básica es la familia y siempre ha tenido más importancia que el trabajo, la política o cualquier diversión social, por eso es frecuente escuchar la frase: "Mi familia es lo más apreciado." Dentro de la familia tradicional el padre es el que trabaja fuera de casa para ganar dinero y mantener a su familia mientras que la madre tiene el papel de cuidar a la familia; así que ella trabaja dentro de la casa. Ella es la persona esencial para todo ya que planea las comidas diarias, los horarios de los hijos con sus inquietudes y, cuando hay problemas hace de intermediaria entre el padre y los hijos. Obviamente, el padre respeta esta posición tan especial que tiene la 
madre dentro del núcleo familiar aunque tradicionalmente mantiene un papel dominante, tiene una gran autoridad sobre los hijos y es el encargado de disciplinarles. Como es común que los abuelos o los tíos vivan en el núcleo familiar, los hijos aprenden de sus padres a tratar con cariño a los otros familiares en ese contacto intimo diario, y así desde pequeños comprenden la necesidad de llevarse bien con todos los miembros de la gran familia.

'In the Hispanic world the basic unit is the family, which has held more importance tan work, politics, or any other social activity, and as such, it is frequent to hear the phrase: "My family is what I appreciate the most." Within the traditional family the father works outside of the house to earn money and support his family while the mother has the role of taking care of the family; so she works in the house. She is the essential person for everything because she plans daily meals, the schedules of children and their worries, and, when there are problems, she plays the role of intermediary between father and children. Obviously, the father respects this special position that the mother holds within the nuclear family even though he traditionally maintains the dominant role, meaning he has a great amount of authority over the children and is responsible for disciplining them. Since it is common that grandparents or aunts/uncles live with the nuclear family, children learn from their parents how to treat other family members with love during their close daily contact, and therefore from a young age children understand the necessity of getting along well with all members of the great family.'

\section{REFERENCES}

[1] Beckman, Mary, and Janet Pierrehumbert. (1986). Intonational structure in Japanese and English. Phonology Yearbook, 3, 255309.

[2] Beckman, Mary, Manuel Díaz-Campos, Julia Tevis McGory, and Terrell Morgan. (2002). Intonation across Spanish, in the Tones and Break Indices framework. Probus, 14, 9-36.

[3] Boersma, Paul, and David Weenink. (2009). Praat: doing phonetics by computer. University of Amsterdam.

[4] Chaudron, Craig. (1988). Teacher talk in second-language classrooms. In Craig Chaudron (Ed.), Second language classrooms. (pp. 50-89). Cambridge: Cambridge University Press.

[5] Chun, Dorothy. (2002). Discourse intonation in L2: From theory and research to practice. Amsterdam: John Benjamins.

[6] Contreras, Heles. (1964). ¿Tiene el español un acento de intensidad? Boletín del Instituto de Filología de la Universidad de Chile, 16, 237-239.

[7] Davies, Mark. (2002). Corpus del español. http://www.corpusdelespanol.org/

[8] De la Mota, Carme. (1995). La representación gramatical de la información nueva en el discurso. Doctoral dissertation, Universitat Autònoma de Barcelona.

[9] De la Mota, Carme. (1997). Prosody of sentences with contrastive new information in Spanish. In Antonis Botinis, Georgios Kouroupetroglou, and George Carayiannis (Eds.), Intonation: Theory, models and applications, an ESCA workshop. (pp. 7578). Athens, Greece: ESCA.

[10] Ellis, Rod. (1994). The study of second language acquisition. Oxford: Oxford University Press.

[11] García-Lecumberri, María Luisa. (1995). Intonational signalling of information structure in English and Spanish: A comparative study. Doctoral dissertation, University College of London.

[12] Face, Timothy. (2000). Prosodic manifestations of narrow focus. Southwest Journal of Linguistics, 19, 45-62.

[13] Face, Timothy. (2001). Intonational marking of contrastive focus in Madrid Spanish. Doctoral dissertation, The Ohio State University.

[14] Face, Timothy. (2002). Local intonational marking of Spanish contrastive focus. Probus, 14, 71-92.

[15] Face, Timothy. (2003). Intonation in Spanish declaratives: differences between lab speech and spontaneous speech. Catalan Journal of Linguistics, 2,115-131.

[16] Face, Timothy. (2006). Narrow focus intonation in Castilian Spanish interrogatives. Journal of Language and Linguistics, 5, 295-311.

[17] Face, Timothy, and Pilar Prieto. (2007). Rising accents in Castilian Spanish: A revision of Sp-ToBI. Journal of Portuguese Linguistics, 6(1), 117-146.

[18] Face, Timothy. (2010). Perception of Castilian Spanish intonation: Three challenges for intonational phonology. Paper presented at Laboratory Approaches to Romance Phonology, Brigham Young University, Provo, Utah.

[19] Faraco, Martine, Tsuyoshi Kida, Marie-Laure Barbier, and Annie Piolat. (2002). Didactic prosody and notetaking in L1 and L2. In B. Bel and I. Marlien (Eds.), Proceedings of Speech Prosody 2002. (pp. 287-290). Aix-en-Provence, France: Laboratoire Parole et Langage, Université de Provence.

[20] Fernald, Anne. (1989). Intonation and communicative intent in mothers' speech to infants: Is the melody the message? Child Development, 60, 1497-1510.

[21] Fernald, Anne, and Claudia Mazzie. (1991). Prosody and focus in speech to infants and adults. Developmental Psychology, 27, 209-221.

[22] Garrido, Juan M. (1996). Modelling Spanish intonation for text-to-speech applications. Doctoral dissertation, Universitat Autònoma de Barcelona.

[23] Garrido, Juan M., Joaquim Llisterri, Carme de la Mota, Rafael Marín, and Antonio Ríos. (1995). Prosodic markers at syntactic boundaries in Spanish. In Kjell Elenius and Peter Branderud (Eds.), Proceedings of the XIIIth International Congress of Phonetic Sciences Vol. 2. (pp. 370-373). Stockholm: KTH and Stockholm University.

[24] Gerard, Claire, and Delphine Dahan. (1995). Durational variations in speech and didactic accent during reading. Speech Communication, 16(3), 293-311.

[25] Giles, Howard. (1980). Accommodation theory: Some new directions. York Papers in Linguistics, 9, 105-136.

[26] Gussenhoven, Carlos. (2004). The phonology of intonation. Cambridge: Cambridge University Press. 
[27] Henriksen, Nicholas, Kimberly L. Geeslin, and Erik W. Willis. Forthcoming. The effects of a home-stay program in León, Spain on L2 Spanish intonation: Global contours and final boundary movements. Studies in Hispanic and Lusophone Linguistics.

[28] Hualde, José Ignacio. (2002) Intonation in Spanish and the other Ibero-Romance languages. In Caroline Wiltshire and Joaquim Camps (Eds.), Romance phonology and variation. (pp. 101-115). Philadelphia: John Benjamins.

[29] Hualde, José Ignacio. (2003). El modelo métrico y autosegmental. In Pilar Prieto (Ed.), Teorías de la entonación. (pp. 155-184). Barcelona: Ariel.

[30] Hualde, José Ignacio. (2007). Stress removal and stress addition in Spanish. Journal of Portuguese Linguistics, 6 (1), 59-89.

[31] Hualde, José Ignacio. (2009). Unstressed words in Spanish. Language Sciences, 31(2-3), 99-112.

[32] Kijak, Anna. (2009). How stressful is L2 stress? Doctoral dissertation, Netherlands Graduate School of Linguistics.

[33] Kimura, Takuya. (2006). Mismatch of stress and accent in spoken Spanish. In Yuji Kawaguchi, Ivan Fonágy, and Tsunekazu Moriguchi (Eds.), Prosody and syntax: Cross-linguistic perspectives. (pp. 141-155). Amsterdam: Benjamins.

[34] Ladd, Robert. (1996). Intonational phonology. Cambridge, UK: Cambridge University Press.

[35] Ladd, Robert. (2008). Intonational phonology, second edition. Cambridge, UK: Cambridge University Press.

[36] Lipski, John. (1994). Latin American Spanish. London: Longmans.

[37] Mannon, T.M. (1986). Teacher talk: A comparison of teacher's speech to native and non-native speakers. MA thesis, University of California, Los Angeles.

[38] Marín Gálvez, Rafael. (1994). La duración vocálica en español. E.L.U.A., 10, 213-226.

[39] Navarro Tomás, Tomás. (1944). Manual de entonación española. New York: Hispanic Institute in the United States.

[40] Navarro Tomás, Tomás. (1964). La medida de la intensidad. Boletín del Instituto de Filología de la Universidad de Chile, 16, 231-235.

[41] Nibert, Holly J. (2000). Phonetic and phonological evidence for intermediate phrasing in Spanish intonation. Doctoral dissertation, University of Illinois, Urbana-Champaign.

[42] O'Rourke, Erin. (2005). Intonation and language contact: A case study of two varieties of Peruvian Spanish. Doctoral dissertation, University of Illinois at Urbana-Champaign.

[43] O'Rourke, Erin. (2006). The direction of inflection: Downtrends and uptrends in Peruvian Spanish broad focus declaratives. In Manuel Díaz-Campos (Ed.), Selected proceedings of the 2nd conference on Laboratory Approaches to Spanish Phonetics and Phonology. (pp. 62-74). Somerville, MA: Cascadilla Proceedings Project.

[44] Ortega-Llebaria, Marta. (2006). Phonetic cues to stress and accent in Spanish. In Manuel Díaz-Campos (Ed.), Selected proceedings of the 2 nd conference on Laboratory Approaches to Spanish Phonetics and Phonology. (pp. 104-118). Somerville, MA: Cascadilla Proceedings Project.

[45] Ortega-Llebaria, Marta, and Pilar Prieto. (2007). Disentangling stress from accent in Spanish: Production patterns of the stress contrast in deaccented syllables. In Pilar Prieto, Joan Mascaró, and Maria Josep Solé (Eds.), Segmental and prosodic issues in Romance phonology. (pp. 155-175). Amsterdam: John Benjamins.

[46] Ortega-Llebaria, Marta, Pilar Prieto, and María del Mar Vanrell. (2007). Perceptual evidence for direct acoustic correlates of stress in Spanish. In Jürgen Trouvain and William J. Barry (Eds.), Proceedings of the XVIth International Congress of Phonetic Sciences. (pp. 1121-1124). Dudweiler: Pirrot GmbH.

[47] Papoušek, Mechthild, Hanuš Papoušek, and David Symmes. (1991). The meanings of melodies in motherese in tone and stress languages. Infant Behavior and Development, 14, 415-440.

[48] Pierrehumbert, Janet. (1980). The phonology and phonetics of English intonation. Doctoral dissertation, MIT.

[49] Pierrehumbert, Janet, and Mary Beckman. (1988). Japanese tone structure. Cambridge, MA: MIT Press.

[50] Pierrehumbert, Janet, and Julia Hirschberg. (1990). The meaning of intonational contours in the interpretation of discourse. In Philip Cohen, Jerry Morgan and Martha Pollack (Eds.), Intentions in Communication. (pp. 271-311). Cambridge, MA: MIT Press.

[51] Prieto, Pilar, Holly Nibert, and Chilin Shih. (1995). The absence or presence of a declination effect on the descent of F0 peaks?: Evidence from Mexican Spanish. In Karen Zagona (Ed.), Grammatical theory and Romance languages. (pp. 197-207). Philadelphia: John Benjamins.

[52] Prieto, Pilar, Chilin Shih, and Holly Nibert. (1996). Pitch downtrend in Spanish. Journal of Phonetics, 24, 445-473.

[53] Prieto, Pilar. (1998). The scaling of the L values in Spanish downstepping contours. Journal of Phonetics, 26, 261-282.

[54] Quilis, Antonio. (1993). Tratado de fonología y fonética españolas. Madrid: Gredos.

[55] Rao, Rajiv. (2006). On intonation's relationship with pragmatic meaning in Spanish. In Timothy L. Face and Carol A. Klee (Eds.), Selected proceedings of the 8th Hispanic Linguistics Symposium. (pp. 103-115). Somerville, MA: Cascadilla Press.

[56] Rao, Rajiv. (2009). Deaccenting in spontaneous speech in Barcelona Spanish. Studies in Hispanic and Lusophone Linguistics, 2(1), 31-75.

[57] Rao, Rajiv. (2010). On the prosody of politeness in Spanish. Paper presented at Laboratory Approaches to Romance Phonology, Brigham Young University, Provo, Utah.

[58] Šlédrová, Jašna. (2000). Some features of didactic communication (didactic test specifics). Psycholinguistics on the threshold of the year 2000, 533-535.

[59] Sosa, Juan Manuel. (1999). La entonación del español: su estructura fónica, variabilidad y dialectología. Madrid: Cátedra.

[60] Toledo, Guillermo. (1989). Señales prosódicas del foco. Revista Argentina de Linguística, 5, 205-230.

[61] Toledo, Guillermo. (2000). H en español de Buenos Aires. Langues e Linguistique, 25, 107-127.

[62] Trainor, Laurel, and Renée Desjardins. (2002). Pitch characteristics of infant-directed speech affect infants' ability to discriminate vowels. Psychonomic Bulletin \& Review, 9(2), 335-340.

[63] Uther, Maria, Monja Knoll, and Denis Burnham. (2007). Do you speak E-N-G-L-I-S-H? A comparison of foreigner- and infant-directed speech. Speech Communication, 49(1), 2-7.

[64] Willis, Erik. (2003). The intonational system of Dominican Spanish: Findings and analysis. Doctoral dissertation, University of Illinois, Urbana-Champaign. 
[65] Yanfen, Liu and Zhao Yuqin. (2010). A study of teacher talk in interactions in English classes. Chinese Journal of Applied Linguistics, 33 (2), 76-86.

[66] Zubizarreta, María Luisa. (1998). Prosody, focus and word order. Cambridge, MA: MIT Press.

Rajiv Rao, whose family is from South India, was born in Arkansas and raised in California (USA). In 2007, he earned his Ph.D. in Spanish Linguistics from the University of California-Davis, in Davis, California. His area of emphasis in his Ph.D. program was phonetics and phonology, especially at the suprasegmental level. He also earned a designated emphasis in second language acquisition.

After working as an ASSISTANT PROFESSOR at Northern Illinois University for 2 years, he moved to the University of Wisconsin-Madison, where he currently holds a position as an ASSISTANT PROFESSOR. He has published in journals such as the Southwest Journal of Linguistics, Studies in Hispanic and Lusophone Linguistics, and The Linguistics Journal. His current investigations of Spanish deal with the prosodic manifestations of stress, and intonation's connection with pragmatic meaning. He is also interested in the phonetics of Palenquero, a Creole language spoken in Colombia.

Dr. Rao is a member of The Linguistic Society of America, The Linguistic Association of the Southwest, and the American Association of Teachers of Spanish and Portuguese. He also is an affiliate faculty member with the Second Language Acquisition and Latin American, Caribbean, and Iberian Studies Programs at the University of Wisconsin-Madison. 